\title{
Como as mães de uma creche domiciliar percebem o trabalho de tomar conta de crianças?
}

\author{
Ana Cristina Coll Delgado \\ Fundação U niversitária do Rio Grande, \\ Departamento de Educação e Ciências do Comportamento
}

\section{Introdução}

Este artigo apresenta parte dos resultados de um estudo de caso etnográfico realizado em uma creche domiciliar ${ }^{1}$ de um bairro popular do Município de São Gonçalo, no Estado do Rio de Janeiro, do ano de 2000 a agosto de $2001 .^{2} \mathrm{O}$ objetivo central do estudo foi

\footnotetext{
${ }^{1}$ Esclareço que esta é uma análise sociológica de práticas sociais de cuidado/educação em ambiente informal, que eu denomino de creche, embora com um sentido diferente do que a legislação estabelece. Não estou tratando do termo "creche domiciliar" enquanto uma instituição legalizada, com fiscalização e estratégias de formação das trabalhadoras. Uso o termo porque o trabalho efetivamente acontece no domicílio da trabalhadora que recebe pagamento mensal das famílias. Compreendo que as designações e nomes são construídos socialmente e o uso do termo creche domiciliar é sociológico, isto é, as palavras correspondem a uma referenciação pelo uso social da linguagem, e não pela adequação à lei, ou científica, do termo.

${ }^{2}$ Trabalho neste texto com uma parte das análises desenvolvidas no terceiro capítulo de minha tese de doutorado: “Toma-se
}

analisar os significados do trabalho de tomar conta de crianças para uma trabalhadora e um grupo de mães, e os desdobramentos desse trabalho no cotidiano. Focalizarei as análises nas trajetórias de vida e profissão das mães, e nos sentidos que elas atribuem ao trabalho de tomar conta de crianças.

Ressalto que o universo de entrevistadas compreende um número reduzido de cinco mães - as quais denomino Elisa, Íris, Juçara, Marta e Laura³ -, pois o

conta de crianças" - Os significados do trabalho e o cotidiano de uma creche domiciliar (Delgado, 2003), orientada pela Professora Doutora Léa Pinheiro Paixão (Universidade Federal Fluminense) e co-orientada pelo Professor Doutor Manuel Jacinto Sarmento (Universidade do Minho, Portugal).

${ }^{3}$ Os nomes de todos os informantes são fictícios. Quando iniciei as observações na creche domiciliar (de junho a agosto de 2001), oito crianças freqüentavam a creche: Daniel, Julinho, Jane, Estela, Mateus, Jonathan, Marcos e Mauro. Jonathan, Marcos e Mauro saíram da creche domiciliar em julho de 2001. Consegui entrevistar: Elisa (mãe de Jane, de 4 anos), diarista, com 34 anos, vivendo com Neuci, de 47 anos; Juçara (mãe de Marcos, com 3 
vaivém das suas condições de existência produz situações de vida muito precárias, com o deslocamento cotidiano para outras cidades ou bairros a fim de trabalhar. Como as mães saem muito cedo e chegam muito tarde do trabalho, não foi possível fazer entrevistas nas suas casas, conforme pretendia. Geralmente na entrada ou na saída das crianças eu solicitava uma entrevista delas, mas por força das circunstâncias e das dificuldades de locomoção no bairro foi Denise, como denomino a tomadora de conta de crianças, quem fez a mediação com as mães e propiciou que elas fossem entrevistadas dentro da creche domiciliar.

Num primeiro momento, analiso os traços que aproximam e os traços que distinguem as mães, considerando seus percursos familiares, as trajetórias de escolaridade e de profissão suas e de seus cônjuges, bem como suas percepções sobre trabalho, casamento e lazer.

Como as cinco mães estabelecem relações com Denise e a creche domiciliar, analiso a seguir suas escolhas, os acordos que são feitos e suas expectativas a respeito da atividade de tomar conta de crianças. Por último, trato dos sentidos que as mães atribuem ao trabalho, o que para mim se traduz em uma perspectiva de educação familiarista, que ocorre por meio da delegação da criação dos filhos à tomadora de conta. Porém, percebo essa delegação como uma estratégia encontrada pelas mães para resolver os dilemas impostos por suas duras condições de existência, e não como algo que possa prejudicar o desenvolvimento emocional das crianças, o que aprofundarei na última parte do artigo.

anos, e Mauro, com 10 meses), empregada doméstica, com 23 anos, casada com João, de 26 anos; Marta (mãe de Daniel, com três anos), faxineira do Serviço Social do Comércio (SESC), com 39 anos, casada com Carlos, de 32 anos; Íris (mãe de Mateus, com 2 anos, e Edílson, com 7), empregada doméstica, com 29 anos, casada com José, de 33 anos; e Laura (mãe de Patrícia, de 3 anos, e Júnior, de 3 meses), empregada doméstica, com 22 anos, vivendo com Renato, de 22 anos.

\section{Traços que aproximam e traços que distinguem as trajetórias de cinco mulheres, mães e trabalhadoras}

As trajetórias de vida das cinco mães estão marcadas pela origem social e pelas relações de gênero. Todas elas têm procurado encontrar estratégias de sobrevivência ante as dificuldades que enfrentam desde a infância. São mulheres, mães e trabalhadoras pertencentes a um grupo social que tem um cotidiano de muito trabalho e de dificuldades para obter empregos com direitos sociais. A inserção em um bairro popular marcado pela violência do tráfico de drogas produz sentimentos como medo, insatisfação e desejo de mudança.

Além disso, nesse universo pequeno de mães também encontrei singularidades nas suas trajetórias, e não posso afirmar ser ele um grupo homogêneo. Juçara, Íris, Marta e Laura residem em terrenos ocupados por outros parentes consangüíneos, exatamente como a tomadora de conta. Essa é uma característica de grupos das camadas populares, consistindo no aproveitamento de lotes para a construção de casas de duas ou mais famílias que pertencem a uma mesma rede de parentesco. Com exceção de Juçara, que está construindo uma casa no mesmo terreno onde residem sua mãe e o irmão, as outras três mães habitam lotes que pertencem às famílias de origem dos cônjuges. Fonseca (1997, p. 536) aponta a natureza aberta da unidade doméstica das famílias de baixa renda, muitas vezes aparente no próprio aspecto da residência, com múltiplas casas no mesmo quintal.

O trabalho precoce faz parte das trajetórias das cinco mães. Elisa começou a trabalhar na lavoura com 11 anos; Juçara, como repositora de mercadorias, com 11 anos; Marta, em uma fábrica de tecidos, com 14 anos; Laura, como vendedora em uma fábrica de flores, com 16 anos; e Íris, como caixa de supermercado, com 17 anos. O ingresso no trabalho representa para todas elas a obtenção de uma renda que permite ou consumir artefatos que as famílias não podem oferecer, ou contribuir para a renda mensal familiar. Igualmente, essas mulheres iniciaram muito cedo a auxiliar 
nos serviços domésticos, e o cuidado dos irmãos menores faz parte da sua rotina de vida desde a infância.

Como há um fluxo de emprego/desemprego bem significativo, principalmente nas vidas de Juçara, Laura e Íris, os condicionantes de classe e gênero podem explicar os seus percursos. Algumas delas trabalhavam em firmas que fecharam, e as possibilidades de encontrar outras profissões com garantias como carteira de trabalho assinada foram reduzindo-se. Quando engravidaram ou casaram, essas chances tornaram-se cada vez menores. Como Laura explicou, para as mulheres com pouca escolaridade é mais difícil encontrar outro serviço, e elas acabam trabalhando como empregadas domésticas, babás ou faxineiras.

Como quatro das mães têm experiências com trabalhos domésticos, vale a pena situar essas atividades no âmbito da sociedade brasileira, tal como propõe Santos (2000). Esta economista explica que o emprego doméstico no Brasil faz parte da história da nossa sociedade, fundada nas discriminações de classe, gênero e raça. Como o trabalho de empregada doméstica prescinde de aprendizagens escolares ou de uma aprendizagem formal, ela questiona se a atividade de empregada doméstica é uma categoria profissional. ${ }^{4}$

Das quatro mães que trabalham com serviços domésticos, nenhuma estava com a carteira assinada no período das entrevistas. Elisa disse contribuir com o Instituto Nacional do Seguro Social (INSS), Juçara e Laura estavam desempregadas e sem carteira assinada, e Íris ainda estava fazendo uma experiência no trabalho.

Como assinala Santos (2000), cerca de 60\% das empregadas domésticas no Brasil não possuem carteira de trabalho. Essas trabalhadoras que não têm carteira de trabalho desenvolvem uma atividade in-

${ }^{4}$ Existem no Brasil cerca de três milhões de empregadas domésticas; a autora explica que, segundo a lei $\mathrm{n}^{\circ}$ 5859/1972, a atividade é oficializada e compreende todo empregado que presta serviço de natureza contínua e de finalidade não-lucrativa a pessoa ou família no âmbito residencial. formal. Ela também chama a atenção para o fato de que, em comparação com outros empregos, as empregadas domésticas não têm uma maior flutuação em suas atividades profissionais do que outras profissões. Foi possível constatar que depois que as mães entrevistadas começaram a trabalhar como domésticas ou faxineiras, não passaram por outros serviços.

Os cônjuges de Marta, Íris e Elisa encontram-se no vaivém do mercado formal e informal, predominando entre eles os serviços gerais e os biscates, além dos longos períodos de desemprego. Somente os cônjuges de Juçara e Laura estavam empregados e com carteira assinada.

Nos casos de Marta, Elisa e Íris, são as mulheres que mantêm a casa e, por isso, seus filhos permanecem na creche domiciliar. Ocorre uma centralização das responsabilidades pelo sustento das famílias entre essas três figuras femininas, que são mantenedoras das famílias durante longos intervalos de tempo. Os casos de Juçara e Laura são diferentes, porque seus maridos é que são os provedores. Contudo, ambas contribuem para as despesas da casa. Laura afirmou que precisa ajudar o cônjuge, que recebe um salário baixo, e Juçara, além de apreciar a oportunidade de sair do âmbito doméstico, trabalha para ajudar o marido na construção da casa.

Logo, o serviço de tomar conta, nesse caso, direciona-se às crianças de mães que exercem profissões domésticas, além dos serviços domésticos que executam nas suas moradias. Potengy e Paiva (1999) explicam que o conceito de trabalho assalariado tornase inadequado para refletir sobre o trabalho feminino em âmbito doméstico, geralmente caracterizado pela dupla ou tripla jornada de trabalho. Elas ressaltam que a dicotomização entre as atividades consideradas como de produção, geralmente centradas no desenvolvimento do trabalho assalariado, e as atividades ligadas à reprodução social dos indivíduos, comumente realizadas por mulheres e nos espaços domésticos, acabou excluindo os estudos sobre trabalho doméstico da esfera econômica.

Não é minha intenção ampliar essas discussões, mas como estou tratando de mães que fazem servi- 
ços domésticos tanto fora como dentro das suas casas, é interessante destacar que há várias estudiosas brasileiras ${ }^{5}$ que investigam o trabalho feminino em âmbito doméstico. Potengy e Paiva (1999) situam o início dos estudos sobre a mulher, com um enfoque no trabalho feminino, no final dos anos de 1960 e início dos anos de 1970. Foi a emergência do movimento feminista que forneceu as condições para a legitimação da condição feminina como objeto de análise. Igualmente, uma corrente de estudos sobre gênero preocupava-se em ampliar as investigações sobre trabalho, incluindo o trabalho doméstico.

De acordo com as mesmas autoras, a crise econômica dos anos de 1980 impulsionou um número cada vez maior de mulheres a aceitar empregos nãoregulamentados, devido às rendas decrescentes das famílias, especialmente na América Latina e na África. As mulheres latinas estão fortemente representadas no setor informal e doméstico. Para essas autoras, as atividades realizadas pelas mulheres no âmbito doméstico fazem parte de um sistema de produção que se aproveita do trabalho feminino, por ser mais barato e definido como tarefa da dona de casa.

Com relação ao que elas escrevem, investiguei um grupo de mães cujo trabalho tem estreita relação com o trabalho dos cônjuges. Uma parte delas enfrenta a situação de trabalho instável dos maridos, desempenhando o papel de mantenedoras das famílias. Mas ainda executam boa parte das tarefas domésticas e responsabilizam-se pela criação dos filhos, os quais, por força das circunstâncias e das limitações que enfrentam na vida diária, delegam a Denise.

\section{Trabalho, casamento e lazer na perspectiva das mães}

Nas trajetórias das mães, os horários de trabalho e as rotinas cotidianas de acordar, levar e buscar os

${ }^{5}$ Além das autoras referenciadas no texto, destaco outras contribuições, como: Bruschini (1985, 1990), Saffioti (1969, 1989), entre outros estudos de igual relevância. filhos na creche, de chegar em casa e ter ainda que trabalhar, ou adiantar as coisas para o dia seguinte, são acontecimentos presentes nas suas vidas.

Uma questão instiga-me: essas mulheres não são provedoras de uma família monoparental, como é o caso da tomadora de conta, mas acumulam tarefas como a de sustentar a família, responsabilizam-se quase que inteiramente pelos filhos na ausência de Denise, e ainda executam os serviços domésticos da casa. Ocorre uma centralização do trabalho doméstico nas mães, e a divisão das tarefas com os cônjuges é quase imperceptível. Provavelmente tenhamos aqui uma das explicações para entendermos por que mulheres como Elisa, Marta e Íris necessitam da creche domiciliar, pois os cônjuges, mesmo quando desempregados, não se responsabilizam pelos filhos e pelos serviços domésticos. Essa é uma estrutura familiar que centraliza todas as decisões na figura da mãe, sobrecarregando essas mulheres. Não posso afirmar, portanto, que encontrei um modelo de família patriarcal, na qual o homem é ao mesmo tempo o chefe e o provedor. Nos casos dessas três mulheres, o que ocorre é que elas são as provedoras e as responsáveis pelos filhos, embora os homens tomem decisões e assumam a posição de chefia.

Lobo (1992) faz uma crítica interessante sobre a produção brasileira que tem relacionado a divisão sexual do trabalho com o patriarcado. Ela discorda da insistência de colocar tal problemática no âmbito do patriarcado e cita Rowbotham(1984), para quem a palavra patriarcado apresenta muitos problemas, pois trabalha com uma forma universal e histórica de opressão, com uma estrutura fixa, enquanto as relações entre homens e mulheres são mutáveis e fazem parte de heranças culturais e institucionais, assim como implicam tanto reciprocidades quanto antagonismos.

Nesse sentido, interessei-me em compreender como essas cinco mães percebem o trabalho e a divisão das tarefas domésticas, o casamento e o lazer. Penso que algo pode justificar por que elas suportam esse excesso de responsabilidades. Para entender essas mães e seus posicionamentos é preciso consi- 
derar que elas são mulheres pobres, que trabalham fora de casa e que se responsabilizam quase que inteiramente pelos serviços domésticos. Isso me remete a duas questões fundamentais.

Primeiro, há um recorte de classe que me ajuda a compreender esse grupo. Elas fazem parte das camadas populares, e alguns estudos brasileiros vinculados à antropologia discutem por que mulheres como Íris, Elisa e Marta necessitam da figura masculina do chefe ou provedor, mesmo quando são elas que assumem tais funções, ainda que temporariamente. $\mathrm{Na}$ sociologia há estudos que questionam por que as mulheres experimentam sentimentos de onipotência com o acúmulo de tarefas (Izquierdo, 1999), o que não pode ser explicado somente pelo viés econômico e pela classe social. $\mathrm{O}$ recorte de gênero permite-me buscar uma visão menos reducionista dos motivos que levam essas mulheres ao acúmulo de tarefas, o que se relaciona com suas percepções sobre divisão sexual do trabalho, casamento e tempo para o lazer.

Lobo (1992) procura situar a importância do uso do gênero como categoria analítica nos estudos sobre trabalho feminino e divisão sexual do trabalho. Ela fundamentalmente defende a articulação da divisão sexual do trabalho com a categoria gênero, no âmbito da sociologia do trabalho, porque é possível uma compreensão das metamorfoses do trabalho, das subjetividades e identidades que são construídas no trabalho, entre outras questões. Outro aspecto que ela discute é que a relação de trabalho, enquanto relação social, traz embutida uma relação de poder entre os sexos.

Embora residindo com os cônjuges, as cinco mães caracterizaram-nos como figuras distantes do trabalho doméstico, da dinâmica familiar e da criação dos filhos, ainda que Elisa, Íris, Juçara e Laura tenham relatado que ocorre algum tipo de ajuda momentânea dos homens, principalmente nos finais de semana. A divisão dos papéis sexuais no trabalho foi alvo de críticas das informantes, mas ao mesmo tempo foi reconhecida como algo naturalizado e difícil de romper.
Como podemos constatar, há diferenças entre as responsabilidades de Elisa, Marta e Íris e as responsabilidades de Laura e Juçara. Laura reconhece que é o homem quem deve trabalhar fora, embora tenha dito que precisa trabalhar outra vez, porque a renda de Renato é insuficiente para sustentar a família. Mas provavelmente Laura ficaria em casa cuidando dos filhos, se a renda de Renato fosse maior. Também posso supor o mesmo a respeito de Marta, que é mantenedora por necessidade; de Elisa, que explicou que uma mulher trabalha quando a renda do cônjuge é insuficiente para manter a família; ou de Íris, que ainda não regularizou a carteira de trabalho e que reconhece a situação profissional instável de José. Somente Juçara afirmou que gosta de trabalhar, mas seus motivos são certamente mais amplos do que aumentar a renda familiar.

O trabalho significa para Juçara uma possibilidade de estabelecer contatos com o mundo da rua, de sair do lar e da convivência com o marido e os filhos para ver pessoas diferentes e experimentar coisas novas, ainda que ela mantenha um discurso de que deseja trabalhar para aumentar a renda da família.

Mas esse modelo de família que, de certa forma, estrutura as vidas das mães e seus cônjuges, não significa que as mulheres são incapazes de exercer poder. Possivelmente, o contato que essas mães mantêm diariamente com mulheres das camadas médias também é elemento formador de concepções de gênero e trabalho não tão rígidas nos discursos, ainda que na prática elas continuem com sobrecarga de trabalho.

O cônjuge de Íris é quem leva o filho para a creche domiciliar, assim como ajuda nas tarefas da casa nos finais de semana. Juçara relatou que seu marido é um bom pai e passeia com os filhos nos finais de semana. Elisa disse que quando Neuci está em casa ele oferece atenção a Jane, e também está construindo a casa nova, assim como Laura contou que Renato sai com as crianças para passear nos finais de semana. Mas, como observam os sociólogos portugueses Torres e Silva (1998), em pesquisa sobre a guarda 
das crianças e a divisão do trabalho entre homens e mulheres na região da Grande Lisboa, tudo se passa mais ao nível do discurso e das boas intenções, do que em mudanças significativas na prática. No Brasil, Berquó (1998) observa que estaria havendo uma tendência à passagem de uma família hierárquica para uma família mais igualitária, tendência mais visível nas camadas médias urbanas e, com o tempo, passando a permear também as camadas populares.

Para as cinco mães, o trabalho fora de casa tornase uma necessidade devido às situações de desemprego dos cônjuges, à instabilidade de renda e aos salários baixos, que não são suficientes para cobrir as despesas das famílias. Ocorre um acúmulo de tarefas para as mulheres que trabalham, porque é necessário oferecer atenção e cuidado aos filhos durante a noite, assim como organizar a casa. Por isso, ao mesmo tempo em que elas reconhecem a dupla jornada de trabalho, também se culpam porque não conseguem dedicar o tempo que sobra para a criação dos filhos.

Torres e Silva (1998) comentam que mães e pais estão cansados e culpabilizados pela menor atenção que consideram dar aos filhos, mas entre as mulheres tal sentimento tem mais força. A concordância com a idéia de que os filhos merecem mais atenção do que a que eventualmente recebem é mais destacada pelas mulheres do que pelos homens. Os autores ainda observam que é nas profissões operárias ou entre os trabalhadores não-qualificados que a idéia de cansaço no trabalho é maior, e que são tanto as mulheres que ocupam profissões que envolvem grande dedicação e correspondem a altos rendimentos quanto as mulheres que ocupam profissões não-qualificadas, mais duras e com baixos rendimentos, que reafirmam a falta de atenção dada aos filhos. Os dados analisados pelos autores demostram as dificuldades de conciliação entre vida familiar e vida profissional, sob o ângulo do cuidado/educação das crianças. A escassez dos equipamentos, a falta de apoio familiar, as baixas remunerações e o sobretrabalho para fazer ante as despesas familiares são fatores apontados no artigo como importantes para explicar declarações tão evidentes de cansaço.
Como não há uma divisão igualitária das tarefas domésticas e dos cuidados dos filhos entre estas mães e os cônjuges, penso que a culpabilização tende a se expandir, na medida em que elas se sentem impotentes para resolver tantas demandas. A figura da tomadora de conta surge como a substituta das mães.

Certamente essa sobrecarga de trabalho, assim como os sentimentos de culpa com relação ao pouco tempo dedicado aos filhos, repercutem na vida diária dessas pessoas. Sem tempo para as crianças e para si, questiono se as mães conseguem dedicar algum tempo de suas vidas ao lazer. Em primeiro lugar, o lazer se restringe ao local no qual residem, porque sair para outros bairros ou cidades demanda maiores recursos econômicos ou tempo, o que é praticamente inviável.

Nenhuma das cinco mães representou o bairro no qual residem como um local que pode ser agradável; ao contrário, seus sentimentos a respeito do bairro são negativos. Principalmente pela violência gerada pelo tráfico de drogas e pela infra-estrutura precária, os desejos das mães refletem a necessidade de mudança do local.

Para Íris, no lugar onde vive não é possível criar um filho com liberdade ou deixar uma criança sozinha. Ela definiu o local como desprovido de segurança, porque há pessoas envolvidas com o tráfico e que andam armadas na frente das crianças. Esse é um traço encontrado por antropólogos que pesquisam bairros populares, como Romanelli (1997), quando observa que hoje as famílias de pobres e trabalhadores convivem com outros moradores ligados ao universo da transgressão.

Como escrevem Chinelli e Durão (1999), as novas relações de trabalho modulam horários e regimes de trabalho, ampliam turnos em dias da semana tradicionalmente dedicados ao descanso, trazem o trabalho para o âmbito doméstico, difundindo diferentes formas de atividades, nas quais as mulheres tendem a engajar-se cada vez mais.

Tal problemática interfere nas vidas dos familiares das crianças, principalmente entre as mulheres, que têm sobrecarga de trabalho quando trabalham fora 
de casa. Mas há razões não apenas econômicas que podem explicar por que elas acumulam tantas funções, ou vivem relações tensas com os companheiros e mesmo assim continuam casadas.

Penso que essas mães têm um modelo de estrutura de família nuclear que pode explicar por que elas reconhecem a desigualdade na divisão do trabalho entre homens e mulheres, mas não rompem com tal situação. Por que algumas apresentam discursos tão avançados e, mesmo assim, continuam a reproduzir essa divisão? Ou por que três delas sustentam a família quando os homens estão desempregados e fazem praticamente todo o serviço doméstico? Certamente as explicações não são apenas de ordem econômica.

Possivelmente essa é uma estratégia feminina para manter a união com os cônjuges, uma vez que, nos meios populares, quando os homens constituem novas famílias, geralmente reduzem ou perdem o contato com os filhos. Uma outra explicação é que para os homens é mais fácil a recomposição familiar do que para as mulheres. Sobretudo entre as mulheres mais velhas, essa recomposição familiar parece mais difícil, o que não ocorre com os homens mais velhos. E são justamente as mulheres mais velhas em nosso grupo as mantenedoras e responsáveis pelos cuidados da casa.

Como escreve Berquó (1998), o fato de os homens casarem-se com mulheres mais jovens é uma constante praticamente universal, e isso se relaciona com as relações de poder entre os sexos. ${ }^{6}$ Assim, a possibilidade de mobilidade dos homens em várias uniões instáveis é maior, e eles podem dividir-se entre diversas mulheres ao longo dos anos. A autora desta-

${ }^{6}$ Esta autora ainda escreve que "São raros em nosso meio os estudos sobre 'as moedas de troca' oferecidas pelas mulheres e aceitas pelos homens no mercado matrimonial, além da juventude. A persistência do fato mencionado, no caso do Brasil, que conta com um superávit de mulheres em todas as faixas etárias a partir dos 15 anos, tem consequiências diretas no celibato feminino e no avolumado segmento de separadas e viúvas com poucas chances de recasamento" (Berquó, 1998, p. 417). ca que à medida que homens e mulheres avançam em idade, as chances no mercado matrimonial diminuem para as mulheres e aumentam para os homens.

Uma outra explicação para que as mulheres segurem o casamento diz respeito à figura do homem como proteção dentro de casa, num local marcado pela violência, em que as pessoas não confiam no apoio da polícia.

\section{Expectativas das mães quanto à função da tomadora de conta e à creche domiciliar}

Quando as cinco mães entrevistadas trabalham, deixam as crianças aos cuidados de uma mulher que toma conta delas em tempo integral. Como no local onde vivem não existe apenas uma tomadora de conta, elas fazem uma escolha entre as creches domiciliares existentes. As mães procuram justificar suas escolhas estabelecendo comparações com outras creches que não são domiciliares, ou comparando Denise com outras tomadoras de conta. Elas apontam as vantagens que a creche domiciliar oferece, principalmente quanto à flexibilidade dos horários e à atenção proporcionada às crianças.

Porém, é importante esclarecer sobre as opções viáveis no local, principalmente para as crianças maiores de três anos. Ocorre que dentro do bairro não há outra opção para essa faixa etária, além das creches domiciliares. Quando nas entrevistas as mães mencionam as creches gratuitas ou com mensalidades baixas, as informações referem-se às creches filantrópicas ou comunitárias, uma vez que em 2001 existia apenas uma creche pública para crianças maiores de dois anos, em um bairro afastado do local onde realizei o estudo de caso.

Nos primeiros contatos com Denise, as mães estabelecem acordos que são negociados antes mesmo da entrada das crianças na creche domiciliar. A escolha e os acordos são feitos porque elas têm expectativas quanto ao trabalho e à função da tomadora de conta. As mães avaliam esse trabalho e emitem opiniões sobre a vida de Denise, o que demonstra que as escolhas são feitas levando em consideração a pes- 
soa da tomadora de conta enquanto mãe, mulher e trabalhadora.

Esse tomar conta adquire sentidos de afeto, carinho, responsabilidade, controle da alimentação, da higiene, da saúde, do sono, e do desenvolvimento de hábitos e valores de educação em que as crianças devem obedecer às pessoas mais velhas, numa ordem de hierarquia bem definida.

Como o tempo que lhes sobra para o convívio com as crianças é cada vez mais reduzido, as mães preferem encontrar alguém que preencha tais requisitos e ofereça tudo aquilo que elas gostariam de oferecer, mas não podem. Não percebi qualquer intenção das mães de que seus filhos tenham uma experiência educativa mais sistematizada com objetivos de socialização das crianças, ou em atividades pedagógicas mais organizadas. Porém, elas esperam que as crianças possam brincar na creche e demonstram satisfação quando Denise assume uma postura lúdica e carinhosa com os meninos e as meninas.

A afetividade e os cuidados são valorizados, assim como uma educação para a formação de hábitos, valores e atitudes baseados na obediência aos mais velhos. Entretanto, essa entrega dos filhos para a tomadora de conta é algo vivido com culpa, ciúme, ou com uma certa sensação de alívio, como no caso de Juçara. Todos esses sentimentos estão carregados de materialidade, das condições de vida e trabalho dessas mulheres, bem como das suas vivências afetivas e de estratégias para manter a estrutura familiar.

Tais constatações não indicam que as mães não queiram para suas crianças uma escola infantil. Compreendo que todas as atividades de cuidado também são educativas, mas na ótica dessas mães as aprendizagens mais formais são vivenciadas em espaços legalizados de educação.

As famílias das crianças procuram as creches domiciliares como forma de evitar o convívio com a rua, cercada de conflitos gerados pelo tráfico de drogas. A segurança e a proteção das crianças são aspectos norteadores do trabalho desenvolvido no espaço da creche domiciliar. Essa é uma necessidade dos familiares que me parece plenamente incorpora- da pela tomadora de conta e suas ajudantes, no cotidiano vivido com as crianças.

Por último, a tomadora de conta, que cuida das crianças e as protege, também assume a condição de substituir a mãe ou outros familiares nos momentos em que a criança permanece na creche domiciliar: "Substituir uma mãe, o responsável naquelas horas ali, a criança vai ficar aos cuidados daquela pessoa. Fazer o que os responsáveis têm que fazer, o que o pai e a mãe têm que fazer [...]". (Elisa, 21 ago. 2001)

Como podemos observar, as mães valorizam as habilidades da ordem dos cuidados com as crianças. Tais habilidades, para elas, são adquiridas com a experiência e o gosto pela função. Quando questionadas sobre a necessidade de uma formação específica para tomar conta de crianças, Juçara, Laura e Marta responderam que não é necessário, enquanto Elisa e Íris disseram que é importante uma formação que forneça subsídios da psicologia, para que a trabalhadora possa melhor compreender as crianças.

\section{O s sentidos do trabalho para as mães: delegação da função materna e perspectiva familiarista de educação}

Os sentidos do trabalho para as mães se relacionam com suas trajetórias de vida, com o modo como elas vivem as relações familiares com os cônjuges e os filhos. Como a estrutura de família nuclear tem importância nesse grupo, elas desejam que a tomadora de conta possa dar continuidade aos laços de parentesco e à educação do tipo familiar que elas próprias não conseguem oferecer, por suas limitadas condições de existência.

As cinco mães entrevistadas vivem em famílias nucleares constituídas de um casal com filhos. Nesse modelo, geralmente o homem é o provedor e o chefe da família, e as responsabilidades pelos filhos estão centradas quase que exclusivamente na figura feminina. Ocorre que três dessas mães são as provedoras das famílias durante a maior parte do tempo.

Quando as mães trabalham, seja para sustentar a casa, para aumentar a renda familiar ou para conse- 
guir uma cota de felicidade pessoal, como é o caso de Juçara, obviamente não conseguem cuidar dos filhos como gostariam. Percebi que há uma expectativa muito forte em torno da função materna nesse grupo. Ser mãe é viver exclusivamente para os filhos e para o lar. As mulheres que trabalham vivem um dilema: como cuidar da casa e dos filhos e ao mesmo tempo trabalhar para obter uma renda?

Como elas não conseguem resolver esse dilema, porque não há parentes ou vizinhos que possam cuidar das crianças em tempo integral, adotam uma medida paliativa: pagar outra mulher para tomar conta dos filhos.

As mães convivem com a situação dos filhos chamarem Denise de mãe, apesar do ciúme e da culpa. Elas têm explicações e lógicas bem estruturadas a respeito da problemática. $\mathrm{O}$ fato de a maioria delas circular no mesmo quintal dos outros parentes, assim como as suas crianças circulam na casa de Denise mesmo quando elas não estão trabalhando, possivelmente proporciona esse caráter aberto à situação. Recordo do que escreve Fonseca (1997, p. 536) a respeito do caráter aberto das casas construídas no mesmo quintal, que proporcionam que "as crianças se infiltrem pelas fronteiras dessas casas burlando os limites entre uma família e outra".

Possivelmente as interpretações das mães também se relacionam com uma certa clareza a respeito da temporalidade da situação, pois Denise as substitui no período em que as crianças necessitam da presença de um adulto que as proteja. Certamente haverá um dia em que a figura de Denise não será necessária. Entretanto, isso não significa que algumas mães não sofram com a situação. Ao contrário, esse é um tempo doloroso para algumas delas.

Explorarei duas dimensões que perpassam os sentidos do trabalho de tomar conta de crianças para as mães. A primeira dimensão refere-se às expectativas das mães de que na creche domiciliar ocorra uma educação de tipo familiarista. Esse é um conceito que descobri no estudo de Torres e Silva (1998), que encontram, nos setores menos escolarizados e com menores rendimentos, uma tendência mais familia- rista (deixar as crianças aos cuidados de uma ama, ou de parentes mais próximos) na escolha dos serviços de guarda para as crianças, embora a partir dos três anos esses setores prefiram serviços que preparem para a escolarização, como forma de evitar o insucesso escolar.

A segunda dimensão diz respeito à relação das mães com a creche domiciliar, que caracterizo como uma relação de delegação. Esse é um conceito desenvolvido por Singly e Maunaye (1996), em pesquisa na França sobre mães que delegam os cuidados dos filhos pequenos e doentes a outras pessoas.

Considerando tal contexto, compreendo que as mães transmitem por delegação a função materna que elas não podem exercer em tempo integral para a figura da tomadora de conta. Nesse sentido, conferem alguns direitos a Denise para agir na ausência delas. Tal delegação envolve outras atribuições e responsabilidades, como levar ao pronto-socorro quando necessário, cuidar das crianças quando estão doentes, acompanhar a vida escolar e substituir a mãe em eventos da escola infantil, marcar exames médicos, preparar e controlar a sua alimentação, acompanhar o desenvolvimento de cada uma delas, seus primeiros passos e primeiras palavras, entre outras.

O sentido da creche domiciliar para as cinco mães não é o de uma creche ou pré-escola legalizada. Elas não desejam para os filhos menores de 3 anos experiências pedagógicas mais sistematizadas. Delegam os cuidados e educação dos filhos, em tempo integral, para Denise. Elas querem que ocorra na creche uma educação do tipo familiarista, que seja coerente com os hábitos, valores e atitudes do meio sociocultural de origem das crianças.

Isso, de certa forma, explica porque elas desejam conhecer a vida pessoal da tomadora de conta, o tipo de educação que ela proporciona às filhas, o modo como organiza a vida doméstica e a casa, para depois fazerem suas escolhas. É necessário que haja uma correspondência entre a forma de Denise criar e educar suas filhas com o tipo de cuidados e educação que as mães desejam para os seus filhos, em particular para as filhas. 
Quando as mães dizem preferir que a tomadora de conta trabalhe com um número pequeno de crianças, porque assim elas recebem mais atenção, provavelmente isso tem um outro sentido, que é o de propiciar uma educação familiarista que dê continuidade aos laços de parentesco entre as crianças e Denise. Não é por acaso que elas argumentam que quando as crianças chamam Denise de mãe, isso representa satisfação pelo carinho e atenção que recebem na creche. Elisa explicou tal sentimento de certa forma com preconceitos, quando disse que é melhor chamar Denise de mãe do que de madrasta.

Nesse sentido, a transmissão/delegação da função materna, que precipitadamente poderia ser classificada como prejudicial ao desenvolvimento das crianças, para as cinco mães é algo encarado com naturalidade, ainda que elas experimentem sentimentos como ciúme e culpa. Tais sentimentos têm uma explicação que não é apenas de ordem simbólica ou psicológica, mas material. Há condições materiais de trabalho e de existência que não permitem a essas mulheres passar um tempo maior com os filhos para fazer coisas divertidas e brincar, por exemplo.

Para essas mães, quando as crianças chamam Denise de mãe, dentro da creche, e de tia, na presença dos pais, ou quando chamam Denise de mãe II, e a mãe de origem de mãe I, isto adquire um sentido: elas estão sendo bem tratadas e gostam da tomadora de conta. Esse é o termômetro que permite medir a temperatura dessa delegação da função materna. É por isso que as mães não levam tal problemática para a creche domiciliar. Elas resolvem o problema do ciúme e da culpa conversando com os filhos ou deixando o tempo passar, porque certamente, quando forem maiores, saberão distinguir quem é a mãe de origem. Não compreendo tal situação como um problema insolúvel ou como algo que possa prejudicar o desenvolvimento emocional das crianças.

Destaco igualmente que viver em um bairro considerado "barra pesada" produz sentidos e expectativas de que a creche domiciliar ofereça proteção às crianças. Não é possível ignorar esse contexto, no qual a violência imprime uma marca social e cultural sobre as vidas humanas.

A violência e a insegurança são marcas nas vidas das mulheres que desejam investir num futuro melhor para os filhos, no sentido de evitar a convivência com o mundo do crime. Matricular uma criança na classe pré-escolar ou de alfabetização em meio período e confiar essa criança a Denise por mais oito ou nove horas significa um investimento. Isso se constitui, contudo, em um investimento diferente daquele das famílias das camadas médias, pois a maior preocupação das mães de origem é afastar as crianças do tráfico, seja pelos cuidados da tomadora de conta, seja pelas expectativas de escolarização que podem favorecer o acesso a um trabalho remunerado.

Fonseca (1993) observa que nas famílias dos meios populares é importante assegurar que certas necessidades objetivas sejam atendidas, mais do que manter uma relação emocional saudável com os filhos, o que é típico das classes médias:

As classes médias atribuem à criança uma série de fases de desenvolvimento emocional e intelectual que exigem, cada uma, cuidados especialmente adaptados e ministrados por adultos específicos. A escola e a família nuclear desempenham os papéis principais de socialização, onde a criança é metida numa estratégia familiar de ascensão socioeconômica a longo termo. Entre meus informantes nunca ouvi preocupação ou fórmulas mágicas ligadas ao desenvolvimento emocional ou aproveitamento escolar. (p. 119)

Denise e as mães das crianças trabalham e responsabilizam-se, parcial ou inteiramente, pela sobrevivência familiar, pela criação dos filhos e pelos serviços domésticos. Elas enfrentam limitações cotidianas geradas pelas condições materiais de existência, o que interfere no simbólico, ou nas formas como elas significam suas vidas e a atividade da creche. É assim que o cansaço decorrente das longas jornadas de trabalho vai misturando-se com os sentimentos de culpa pela menor atenção oferecida aos filhos.

É tenso para todas elas viverem a maternidade $\mathrm{e}$ o trabalho dentro e fora de casa. $\mathrm{O}$ fato de as crian- 
ças chamarem Denise de mãe é tolerado pelas mães de origem e não é discutido no interior da creche. De meu ponto de vista, entre as mães as tensões diluemse em outros sentimentos, como culpa e ciúme. Elas parecem compreender, por exemplo, que aquela é uma relação temporária que pode ser interrompida quando os cônjuges conseguem trabalho e remuneração suficiente para o sustento da família, ou quando as crianças crescem e vão para a escola formal. A frase dita por uma delas: "Ela faz mais do que tomar conta de crianças, ela praticamente cria as crianças" demonstra o reconhecimento das mães de origem quanto ao papel de Denise.

Quando recordo as percepções das mães sobre trabalho, casamento e lazer, a divisão do trabalho doméstico por sexo parece contraditória com a situação socioeconômica das famílias, nas quais predominam mulheres com empregos e salários mais estáveis que os cônjuges. Como explicar as razões que fazem as mulheres persistirem com uma representação simbólica de família na qual o homem é o chefe e o provedor, quando na realidade elas são as que cumprem esses papéis, além do acúmulo dos serviços domésticos? Como dar conta das fragilidades e forças encontradas nos discursos sobre os cotidianos das mulheres? O que, afinal, pode explicar esse emaranhado de relações e sentimentos ambivalentes nos sentidos e modos de existência dessas pessoas?

Sarti (1995) explica uma parte das nossas indagações. É o valor moral dado pelo papel familiar de provedor que dá sentido ao trabalho nos meios urbanos. É esse sentido de trabalhar para a família e não somente para si, que, segundo a autora, pode explicar a valorização do trabalho doméstico pela mulher. Igualmente, o bom trabalhador é o bom provedor, o que também constatamos em nosso estudo quando as mulheres consideram como "bom marido" aquele que trabalha, não joga e não bebe.

Outro aspecto apontado por Sarti em consonância com essas análises diz respeito à lógica da casa em que domina a concepção de trabalho com uma divisão de gênero. É um ethos feminino que rege as relações das mulheres com o trabalho. Nos casos de
Juçara e Marta, percebo que as duas justificam o trabalho para obtenção de "um extra" na família, como a construção dos cômodos da casa ou a compra de roupas, brinquedos e outros artigos para os filhos, ainda que a primeira afirme trabalhar porque necessita viver outras relações além das familiares.

Além disso, há uma incidência de mulheres chefes de família (caso de Denise), ou de baixos salários masculinos (casos de Marta, Elisa e Íris). Nesses casos, o "extra" feminino confunde-se com o fundamental (Sarti, 1995). Com exceção de Juçara, as mães das crianças não mantêm uma relação de prazer com o trabalho, muito pelo contrário. Como escreve Sarti, "a baixa qualificação, baixa remuneração e sobrecarga de trabalho para as trabalhadoras pobres contribuem para tornar o trabalho remunerado muito pouco gratificante [...]" (1995, p. 145).

As mães e Denise confluem na expectativa de que a creche domiciliar seja um espaço que propicie proteção, carinho, alimentação, saúde, resolução de emergências ou acompanhamento das crianças maiores às classes pré-escolares ou classes de alfabetização. A disponibilidade de tempo e a flexibilidade de horários viabilizam a realização de tantas demandas. Nesse aspecto não há tensões e os acordos parecem bem resolvidos entre elas, exceto quando as crianças estão doentes. Quando acontecem tensões que resultam na suspensão dos acordos, a origem delas está nas divergências entre Denise e os familiares quanto à educação das crianças.

Quando afirmo que ocorre uma perspectiva familiarista de educação na creche de Denise é porque as mães querem que seus filhos fiquem num ambiente mais próximo ao das famílias de origem, com uma pessoa de confiança, com os mesmos hábitos e valores, porque querem que as crianças convivam em um ambiente sem rotinas muito rígidas. Porém, não nos pareceu que as mães queiram uma outra família para os filhos, uma vez que a delegação da criação tem uma temporalidade.

As mães das crianças não têm acesso aos serviços públicos como educação e cuidado dos filhos, e algumas se situam na rede de trabalho informal. São 
todas elas mulheres impossibilitadas de exercer sua cidadania? Prefiro não assumir um posicionamento fechado, porque do ponto de vista das relações dessas mulheres com o Estado, e como cidadãs, ainda há muitas dificuldades para superar. Mas não podemos esquecer que no momento em que elas criam estratégias de educação dos filhos e de sobrevivência no cotidiano, estão, de certa forma, exercendo sua cidadania.

A atividade aqui analisada é uma atividade social e comunitária e, embora não legalizada, é legitimada por grupos da população. Não sendo uma proposta de educação infantil formal, a creche domiciliar estrutura-se principalmente para atender às demandas de trabalho e às necessidades dos familiares das crianças e de Denise, que preferiu trabalhar em casa e cuidar das filhas. Parece um aspecto fundamental para compreendermos os significados do trabalho de tomar conta de crianças.

Penso que é necessário considerar os contextos sociais, os anseios e as expectativas dos grupos sem acesso aos serviços de cuidado/educação na elaboração das políticas públicas. As mães preferem espaços menores, com um número reduzido de crianças, sem um tempo excessivamente planejado e programado. Elas valorizam o relacionamento mais íntimo entre Denise e as crianças, assim como desejam um cuidado amoroso, atenção e contato físico. Essas questões merecem reflexão, pois constato que os familiares das camadas populares também são capazes de refletir sobre o cuidado/educação das crianças.

Para finalizar, meu percurso foi o de contemplar esse trabalho e, sem idealizações ou romantismos, examinar seus riscos, mas também as suas possibilidades. Nesse movimento penso haver contribuído para o campo da educação infantil, pois nem sempre priorizamos nas pesquisas os atores sociais à margem das políticas públicas.

$\mathrm{O}$ estudo de caso indica que aquilo que existe e funciona, ainda que na precariedade, não pode mais ser ignorado. $\mathrm{O}$ crescimento de espaços educativos privados para grupos das camadas mais pobres é resultante de uma pressão e uma demanda da popula- ção. Talvez seja o momento de iniciar um levantamento nacional sobre espaços não-formais de cuidado/ educação, com uma caracterização das trabalhadoras, das famílias, das crianças e das condições dos locais. Tal levantamento justifica-se na medida em que as redes paralelas de educação infantil demonstram que há uma pressão da população por esses serviços. Provavelmente outros estudos sobre experiências como essa permitam verificar o que ocorre nesses espaços e quais soluções devem ser propostas.

ANA CRISTINA COLL DELGADO, doutora em educação pela Universidade Federal Fluminense, é professora adjunta no Departamento de Educação e Ciências do Comportamento da Fundação Universitária do Rio Grande. Últimas publicações: Culturas infantis e dimensões de socialização no cotidiano de uma creche domiciliar. Cadernos de Educação. Faculdade de Educação da Universidade Federal de Pelotas, v. 21, ano 12, 2003, p. 101-118; Infâncias e crianças: o que nós adultos sabemos sobre elas? In: Centro de Documentação e Informações Sobre a Criança (CEDIC). Textos de Trabalho. Lisboa, 2004, p. 1-9; DELGADO, A. C. C., MOTA, M. R. A., ALBUQUERQUE, S.S. (orgs.), 2004. Tempos e lugares das infâncias: educação infantil em debate. Porto Alegre: Instituto Popular Porto Alegre; As creches domiciliares são uma alternativa para o cuidado das crianças pequenas? Revista Pátio Educação Infantil. Infância Hoje. Ed. Artmed. Ano 2, no 6 dez. 2004-mar. 2005. (Seção Polêmica). Dedica-se a estudos e pesquisas em educação de crianças de 0 a 6 anos, responsabilizando-se atualmente pelos projetos: Infâncias, crianças e culturas infantis e Metodologias investigativas com crianças.E-mail: anacoll@uol.com.br

\section{Referências bibliográficas}

BERQUÓ, Elza, (1998). Arranjos familiares no Brasil: uma visão demográfica. In: SCHWARCZ, Lília Moritz (org.). História da vida privada no Brasil - v. 4. Rio de Janeiro: Companhia das Letras, p. 411-437.

BRUSCHINI, Cristina, (1985). Mulher e trabalho: uma avaliação da década da mulher. São Paulo: Nobel. (1990). Mulher, casa e família: cotidiano nas camadas médias paulistanas. São Paulo: FCC.

CHINELLI, Filippina, DURÃO, Anna Violeta, (1999). Novos 
Como as mães de uma creche domiciliar percebem o trabalho de tomar conta de crianças?

conteúdos, nova forma e nova cultura do trabalho. Contemporaneidade e Educação, Rio de Janeiro, n 6, p. 99-119.

CHINELLI, Filippina, PAIVA, Elizabeth, (1999). Emprego e informalidade. Contemporaneidade e Educação, Rio de Janeiro, no 6, p. 61-72.

DELGADO, Ana Cristina Coll, (2003). “Toma-se conta de crianças”. Os significados do trabalho e o cotidiano de uma creche domiciliar. Tese de Doutorado, Faculdade de Educação da Universidade Federal Fluminense.

FONSECA, Claudia, (1995). Amor e família: vacas sagradas da nossa época. In: RIBEIRO, Ivete; RIBEIRO, Ana Clara Torres (orgs). Família em processos contemporâneos: inovações culturais na sociedade brasileira. São Paulo: Loyola. p. 69-89.

, (1993). Criança, família e desigualdade social no Brasil. In: RIZZINI, Irene (org.). (1993). A criança no Brasil hoje: desafio para o $3^{\circ}$ milênio. Rio de Janeiro: Editora Santa Úrsula, p. 111-131.

, (1997). Ser mulher, mãe e pobre. In: PRIORE, Mary

Del (org.). História das mulheres no Brasil. São Paulo: Contexto. p. 510-553.

IZQUIERDO, María Jesús, (1999). Del elogio de la diferencia y la crítica de la desigualdad a la ética de la similitud. Revista de Sociologia, Barcelona, n 59, p. 25-49.

LOBO, Elizabeth Souza, (1992). O trabalho como linguagem: o gênero do trabalho. In: COSTA, Albertina, BRUSCHINI, Cristina (orgs.). Uma questão de gênero. Rio de Janeiro/São Paulo: Rosa dos Tempos, p. 252-265.

POTENGY, Gisélia, PAIVA, Vanilda, (1999). Gênero, trabalho doméstico e espaço privado como fonte de produção de mer- cadorias e serviços. Contemporaneidade e Educação, Rio de Janeiro, nº 6 , p. 106-119.

ROMANELLI, Geraldo, (1997). Famílias de classes populares: socialização e identidade masculina. Cadernos de Pesquisa, São Paulo, no 1-2, p. 25-31.

ROWBOTHAM, Sheila, (1984). Lo malo del "patriarcado". In: SAMUEL, R. Historia popular y teoría socialista. Barcelona: Crítica, 1984.

SAFFIOTI, Heleieth, (1969). A mulher na sociedade de classes: mito e realidade. São Paulo: Quatro Artes. , (1989). Emprego doméstico e capitalismo. Petrópolis: Vozes.

SANTOS, Anna Lúcia Florisbela, (2000). O reconhecimento do trabalho doméstico no Brasil. Direito e Cidadania. Lisboa, $n^{\circ} 9$, p. 131-144.

SARTI, Cynthia Andersen, (1995). O valor da família para os pobres. In: RIBEIRO, Ivete, RIBEIRO, Ana Clara Torres (orgs.). Família em processos contemporâneos: inovações culturais na sociedade brasileira. São Paulo: Loyola, p. 131-150.

SINGLY François de, MAUNAYE, Emmanuelle (1996). Le rôle et sa délégation. In: KAUFMANN, Jean-Claude (org). Faire ou faire-faire? Famille et services. Paris: Presses Universitaires de Rennes, p. 93-107.

TORRES, Anália Cardoso, SILVA, Francisco Vieira, (1998). Guarda das crianças e divisão do trabalho entre homens e mulheres. Sociologia - Problemas e Práticas. Lisboa, no 28, p. 9-63.

Recebido em março de 2004 Aprovado em agosto de 2004 


\section{Resumos/Abstracts}

Ana Cristina Coll Delgado

Como as mães de uma creche domiciliar percebem o trabalho de tomar conta de crianças?

O presente artigo tem como objetivo analisar as trajetórias de vida e profissão de um grupo de mães e os sentidos que elas atribuem ao trabalho de tomar conta de crianças em uma creche domiciliar, no município de São Gonçalo (RJ). O referencial teórico abrange estudos da sociologia e antropologia voltados para famílias das camadas populares, gênero, trabalho e educação. As análises evidenciam que os sentidos traduzem uma perspectiva familiarista de educação, que ocorre por meio da delegação da criação dos filhos à tomadora de conta de crianças.

Palavras-chave: creche domiciliar; famílias das camadas populares; trabalho; casamento; delegação; educação

How the mothers of a home-based crèche in São Gonçalo/RJ perceive the work of looking after children?

The objective of the present article is to analyse the professional and life trajectories of a group of mothers and the meaning which they attribute to the work of looking after children in a home-based crèche in the municipality of São Gonçalo in the state of Rio de Janeiro. The theoretical framework includes sociological and anthropological studies on working class families, gender, work and education. The analysis reveals that the meanings translate a family-oriented perspective of education, which takes place by means of the delegation of the responsibility for raising children to those looking after them.

Key-words: home-based crèche; working class families; work; marriage; delegation; education 